\title{
Coronavirus disease 2019 (COVID-19) in Brasil: information to physical therapists
}

\author{
Dodrigo Pegado ${ }^{1}$ \\ (iD) Edson Silva-Filho' \\ (DIllia Nadinne D. F. Lima' \\ (iD Lucien Gualdi
}

1. Programa de pós-graduação em Ciências da Reabilitação, Universidade Federal do Rio Grande do Norte, Natal, RN, Brasil.

http://dx.doi.org/10.1590/1806-9282.66.4.498

\section{SUMMARY}

The emergence of the Coronavirus Disease 2019 (COVID-19) pandemic shows a rapid increase in cases and deaths. The World Health Organization (WHO) has shown that more than 200.000 confirmed cases have been identified in more than 166 countries/territories. Public health authorities in Brasil have reported 532 confirmed cases by March 19. Approximately 5\% of the patients will require intensive care unit treatment with oxygen therapy and mechanical ventilation. Limited data are available about rehabilitation protocols for severe illness and intensive care treatment of COVID-19 increase. Thus, we aim to show current information about COVID-19, describing symptoms and the respiratory management for critical patients and preventive care. Physical therapists and all health care professionals need to recognize the challenges they will face in the coming months.

KEYWORDS: Coronavirus infections. Respiratory distress syndrome, adult. Respiratory therapy.

\section{INTRODUCTION}

The coronavirus (COVID-19 or 2019-CoV) infection became a critical illness and is considered a pandemic infectious disease with high transmissibility'. In December 2019, a series of pneumonia cases of unknown cause emerged in Wuhan. In less than 4 months, several countries, including Brasil, identified the pathogen of COVID-192. Confirmed cases in Brasil are increasing and the COVID-19 outbreak challenges both healthcare personnel and the medical supply system. Physical therapists are directly involved in the treatment of suspect and confirmed cases with an important role in Intensive Care Units (ICU). At the moment, no specific consensus or guidelines have been published regarding ICU protocols, and only a few articles reporting several cases from China and other Asian countries have supported the management of infected patients with respiratory disorders.

Thus, we have described key information according to clinical features pandemic infectious disease for physical therapists describing the main symptoms and respiratory treatments for patients with COVID-19.

\section{CLINICAL CHARACTERISTICS}

To differentiate COVID-19 from other circulating respiratory viruses is extremely important to epidemiologic studies and clinical management ${ }^{3}$. Confirmed cases of COVID-19 result in clinical priority and lead to the implementation of efficient infection control practices. Initial data estimate that $50-70 \%$ of cases 
are asymptomatic at the time of diagnosis ${ }^{4}$. It has been estimated that $86 \%$ of all infections were undocumented and these individuals may have infected up to $79 \%$ of documented cases ${ }^{4}$. The current estimated mean incubation period is 6.4 days, ranging from 2.1 days to 11.1 days and even asymptomatic patients can transmit COVID-195.

The most common symptoms at illness onset are fever and cough ${ }^{5}$. Other common symptoms include shortness of breath (dyspnea), myalgia or fatigue, sputum production, chest tightness, headache, hemoptysis, and diarrhea ${ }^{5}$. Disease onset may result in pneumonia, progressive respiratory failure due to alveolar damage, hyperthermia, decreased lymphocytes and white blood cells count, and new pulmonary infiltrates ${ }^{6}$. Clinical symptoms of COVID-19 according to disease severity are shown in figure 1 . Studies performed in China with severe cases of COVID-19 suggest that the mean number of days from the appearance of the first symptom to death was 14 days $^{5}$.

\section{GENERAL CARE FOR COVID-19 INFECTION}

Most people with COVID-19 develop mild or uncomplicated illness (81\%); however, 14\% develop severe symptoms that require hospitalization and oxygen support, and 5\% will require ICU treatment (figure 1$)^{5}$.

Patients with mild disease may not require hospital interventions unless there is concern about rapid deterioration; however, home isolation is necessary to avoid transmission ${ }^{2}$. All health professionals, including respiratory therapists, must consider the suitability for home care. Moreover, the patient and other household members must have access to appropriate minimum personal protective equipment (gloves and facemasks) and be capable of adhering to recommended precautions (respiratory hygiene and cough etiquette, as well as adequate hand hygiene $)^{5}$. Such patients must also be advised about the signs and symptoms of disease complications.

High Flow Nasal Oxygen (HFNO) and Non-Invasive Ventilation (NIV) are part of the clinical practice of respiratory therapists and may be used in case of limited access to mechanical ventilation and in selected patients prior to the development of severe hypoxemic respiratory failure ${ }^{3}$. It is important to highlight that systems with good interface fitting do not create widespread dispersion of exhaled air, and their use can be considered at low risk of airborne transmission ${ }^{3}$. Although there is no consensus regarding the use of NIV in patients with COVID-19, limited data suggest a high failure rate in other viral infections such as MERS-CoV ${ }^{3}$. Evidence-based guidelines on HFNO do not exist, and reports on HFNO in patients infected with other coronaviruses are limited ${ }^{7}$. Respiratory therapists must also consider, along with other health professionals, that all hospitalized patients in use of HFNO or NIV need regular monitoring of vital signs and clinical deterioration as supportive care interventions may be necessary?

Until now, no consensus or guidelines have been previously published about ICU protocols for mechanical ventilation in patients with COVID-19. Some recommendations are frequently based on the clinical characteristics presented by patients of other

FIGURE 1. CLINICAL SYMPTOMS ASSOCIATED WITH COVID-19. ${ }^{5}$

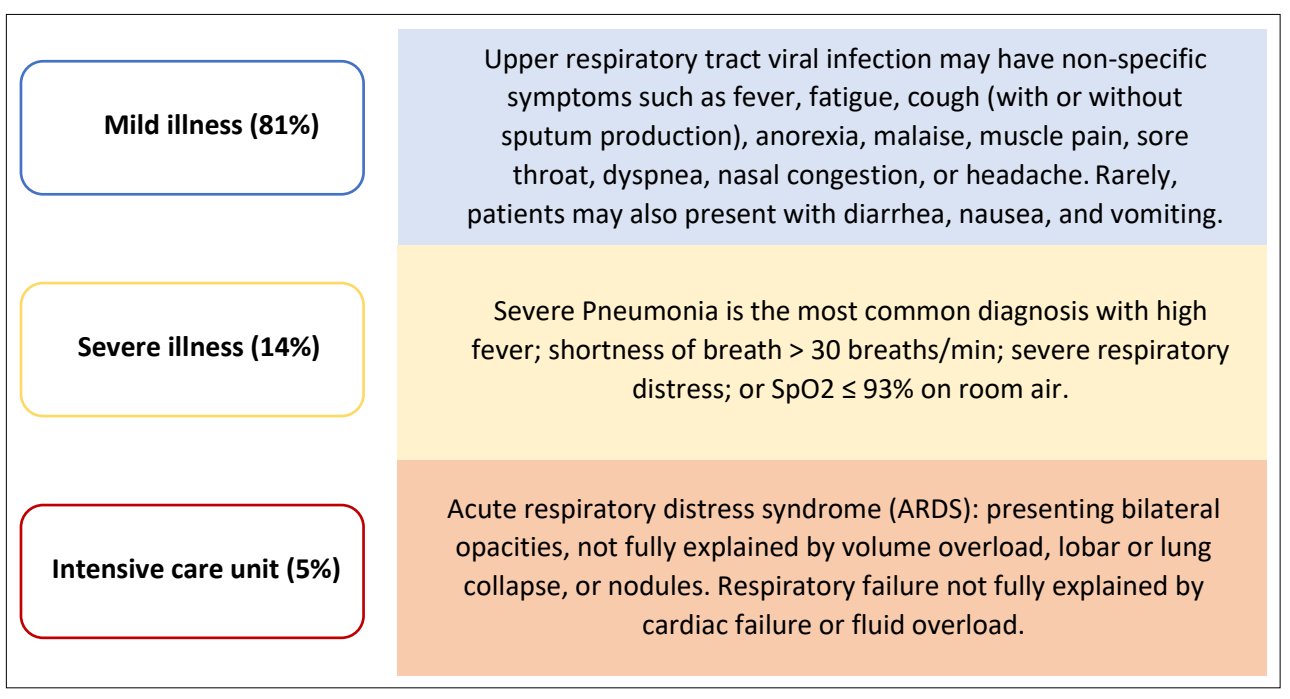


countries who have been exposed to the virus for a longer time ${ }^{5}$. Approximately $5 \%$ will require intensive care unit treatment, and respiratory failure is the main reason for early endotracheal intubation ${ }^{5}$. The aim of invasive ventilation support is to reverse the severe hypoxemia installed ${ }^{8}$. Lung protection ventilation is the main strategy, with volume-controlled or pressure support ventilation models, tidal volume around 4-8 ml/Kg of Predicted Body Weight (PBW) and lower inspiratory pressures (plateau pressure $<30 \mathrm{cmH} 2 \mathrm{O}$ ), aiming at a driving pressure of $10 \mathrm{~cm} \mathrm{H} 2 \mathrm{O}$, or the lowest possible ${ }^{8}$. It is possible that targeting driving pressure may improve safety strategies ${ }^{9}$.

This recommendation is very similar to Acute Respiratory Distress Syndrome (ARDS), (PaO2/FiO2 $\leq 100 \mathrm{mmHg}$ with PEEP $\geq 10 \mathrm{cmH} 2 \mathrm{O}$, or non-ventilated) which recommends supplemental oxygen therapy delivered via a face mask with reservoir bag (flow rates of $10-15 \mathrm{~L} / \mathrm{min}$ ) immediately to patients with respiratory distress, hypoxemia or shock, targeting SpO2 > 94\%. However, some cases have presented little or no changes in lung compliance ${ }^{5}$. Prone positioning has proved to be a primary strategy, and it is recommended for 12-16 hours per day ${ }^{10}$. Prone position significantly reduces mortality in patients with moderate to severe ARDS when used early and for over 16 hours per day in patients receiving protective lung ventilation ${ }^{10}$. Additionally, extracorporeal membrane oxygenation may be considered, although there are no reports of its benefits ${ }^{3}$.

\section{PREVENTIVE CARE, INTENSIVE SURVEILLANCE AND EPIDEMIOLOGICAL INVESTIGATIONS}

Physical therapists have been inserted in the Primary Care of the Brazilian Unified Health System aiming to expand the roles of professionals from Primary Care. Among the strategies that physical therapists develop in this context, preventive and educational actions stand out ${ }^{11}$. It is important to highlight the role of physical therapists as agents of prevention and health promotion who can act directly in helping to control virus dispersion in our country. Physical therapists' performance through health education services with the community, risk factors surveillance, and matrix support favor the containment and early treatment of possible cases in the community ${ }^{11}$.

With regard to health education, physical therapists who have direct contact with the population in spaces such as hospital waiting rooms, health clinics, schools, and other community environments can provide information and guidance on ways to prevent the virus spread, in addition to preparing materials such as informative folders, videos, booklets, and posters to expand the dissemination of information ${ }^{11}$. Therefore, the relevance of physical therapists' work in the Brazilian Unified Health System is highlighted to fight COVID-19, especially in terms of population awareness, surveillance of risk factors, and involvement in collective planning strategies to protect the health of the Brazilian population.

\section{CONCLUSION}

Possibly, Brasil will show an epidemiological trend similar to that of European and Asian countries. All health professionals must be up-to-date and committed to the prevention and treatment of patients with COVID-19. This is an ongoing disease, and little is known about the standard treatment parameters, but it is possible to treat and rehabilitate patients with severe symptoms from COVID-19.

\section{Authors' contributions}

RP: study design, wrote the manuscript, and revised final version.

ESF: wrote the manuscript.

INDFL: wrote the manuscript.

LG: wrote the manuscript.

\section{Declarations of interest}

None. 


\section{RESUMO}

O surgimento da pandemia do Coronavírus 2019 (COVID-19) tem demonstrado rápido aumento dos casos e das mortes. A Organização Mundial da Saúde (OMS) apontou que mais de 200.000 casos confirmados foram identificados em mais de 166 países/territórios. As autoridades de saúde pública no Brasil relataram 532 casos confirmados até 19 de março. Aproximadamente $5 \%$ dos pacientes necessitarão de tratamento em unidade de terapia intensiva com oxigenoterapia e ventilação mecânica. Temos disponíveis dados limitados sobre protocolos de reabilitação para doenças graves e tratamento em unidade de terapia intensiva de pacientes com COVID-19. Assim, nosso objetivo é mostrar informações atuais sobre o COVID-19, descrevendo sintomas e controle respiratório de pacientes críticos e cuidados preventivos. Fisioterapeutas e todos os profissionais de saúde precisam reconhecer os desafios que enfrentaremos nos próximos meses.

PALAVRAS CHAVE: Infecções por Coronavirus. Síndrome do desconforto respiratório do adulto. Terapia respiratória.

\section{REFERENCES}

1. Wu C, Chen X, Cai Y, Xia J, Zhou X, Xu S, et al. Risk factors associated with acute respiratory distress syndrome and death in patients with coronavirus disease 2019 pneumonia in Wuhan, China. JAMA Intern Med. 2020. doi: 10.1001/jamainternmed.2020.0994.

2. Huang $C$, Wang $Y$, Li $X$, Ren L, Zhao I, Hu Y, et al. Clinical features of patients infected with 2019 novel coronavirus in Wuhan, China. Lancet. 2020;395(10223):497-506.

3. Murthy S, Gomersall CD, Fowler RA. Care for critically ill patients with COVID-19. JAMA. 2020. doi: 10.1001/jama.2020.3633.

4. Li R, Pei S, Chen B, Song Y, Zhang T, Yang W, et al. Substantial undocumented infection facilitates the rapid dissemination of novel coronavirus (SARS-CoV2). Science. 2020. doi: 10.1126/science.abb3221.

5. World Health Organization. Clinical management of severe acute respiratory infection (SARI) when COVID-19 disease is suspected. Geneva: World Health Organization; 2020. [cited 2020 Apr 15]. Available from: https://www.who.int/docs/default-source/coronaviruse/clinical-management-of-novel-cov.pdf.
6. Zhou P, Yang XL, Wang XG, Hu B, Zhang L, Zhang W, et al. A pneumonia outbreak associated with a new coronavirus of probable bat origin. Nature. 2020;579(7798):270-3.

7. Qiu H, Tong Z, Ma P, Hu M, Peng Z, Wu W, et al. Intensive care during the coronavirus epidemic. Intensive Care Med. 2020;46(4):576-8.

8. Liew MF, Siow WT, MacLaren G, See KC. Preparing for COVID-19: early experience from an intensive care unit in Singapore. Crit Care. 2020;24(1):83.

9. Wang D, Hu B, Hu C, Zhu F, Liu X, Zhang J, et al. Clinical characteristics of 138 hospitalized patients with 2019 novel coronavirus-infected pneumonia in Wuhan, China. JAMA. 2020. doi: 10.1001/jama.2020.1585.

10. Patel A, Jernigan DB;2019-nCoV CDC Response Team. Initial public health response and interim clinical guidance for the 2019 novel coronavirus outbreak - United States. MMWR Morb Mortal Wkly Rep. 2020;69(5):140-6.

11. Seus TL, Silveira DS, Tomasi E, Thumé E, Facchini LA, Siqueira FV. Estrutura para o trabalho e composição de equipes do Núcleo de Apoio à Saúde da Família: pesquisa nacional - Programa de Melhoria do Acesso e da Qualidade (PMAQ), 2013. Epidemiologia e Serviços de Saúde. 2020;28:e2018510. 